\title{
EFECTOS DE UN PROGRAMA EXPERIMENTAL INTERACTIVO PARA MEJORAR LA COMPRENSIÓN LECTORA EN UNA POBLACIÓN RURAL DE 5. ${ }^{\circ}$ GRADO DE EDUCACIÓN PRIMARIA
}

\author{
EXPERIMENTAL EFFECTS OF AN INTERACTIVE PROGRAM FOR IMPROVING \\ READING COMPREHENSION IN A RURAL POPULATION OF PRIMARY GRADE 5
}

\author{
Lidia Sotelo'; Noemi Sotelo; Carlos Sotelo; María Luisa Matalinares; Carlos Arenas; Tomás Caycho \\ Universidad Nacional Mayor de San Marcos \\ (RECIBIDO 8/1/ 2012; ACEPTADO EL 5/6/2012)
}

\begin{abstract}
RESUMEN
Se reportan los resultados de un estudio experimental, con dos grupos aleatorizados pre y post-test, que busca determinar los efectos de la aplicación de un programa interactivo en la comprensión lectora en niños de 5 to $^{\text {to }}$ primaria de una zona rural de la provincia de Yungay en el departamento de Ancash. El análisis de los datos -recabados mediante la prueba de Comprensión Lectora de Complejidad Lingüística Progresiva (CLP) de Alliende adaptado por Delgado y procesados con el SPSS v. 18- permite concluir que el programa interactivo lector empleado en el grupo experimental ha producido un aumento significativo en sus puntuaciones de comprensión lectora comparándolos con los obtenidos por el grupo control.
\end{abstract}

Palabras clave: Comprensión lectora, programa interactivo lector, estudio experimental.

\begin{abstract}
We report the results of an experimental study with two randomized groups pre and posttest, which seeks to determine the effects of the implementation of an interactive program on the reading comprehension of children in 5th grade in a rural area of the province of Yungay in the Department of Ancash. The analysis of data collected through the Reading Comprehension Test of Linguistic Complexity Progressive (CLP) Alliende, adapted by Delgado and processed with SPSS v. 18, to conclude that the interactive reader used in the experimental group shows a significant increase in reading comprehension scores compared with those obtained by the control group
\end{abstract}

Keywords: reading comprehension, interactive reader, experimental study. 


\section{INTRODUCCIÓN}

En zonas rurales del Perú, con altos índices de pobreza extrema, se presentan características que afectan de forma negativa el curso de desarrollo del niño, apareciendo diferencias en la calidad de vida entre estos y aquellos niños no pobres y bien nutridos (Pollitt, Cueto \& León, 2007, Pollitt \& Caycho, 2010). Estas diferencias se observan también en estudios en el campo de lectura que evidencian un pobre desarrollo de las habilidades de decodificación y comprensión lectora en gran porcentaje de niñas y niños peruanos de zonas menos favorecidas (Cueto, 2007; Morales, Venhoeven \& Van Leeuwe, 2009; Dioses, Evangelista, Basurto, Morales \& Alcántara, 2010). La Figura 1 muestra la relación entre pobreza extrema y rendimiento en comprensión lectora de niños de $2 .^{\circ}$ grado de primaria a nivel nacional, observándose que los departamentos con mayores índices de pobreza extrema presentan menores rendimientos en comprensión lectora. Recordar que esta comparación tiene un valor científico limitado ya que no nos permite describir con precisión las diferencias objetivas en la calidad de vida de los infantes de estos departamentos.

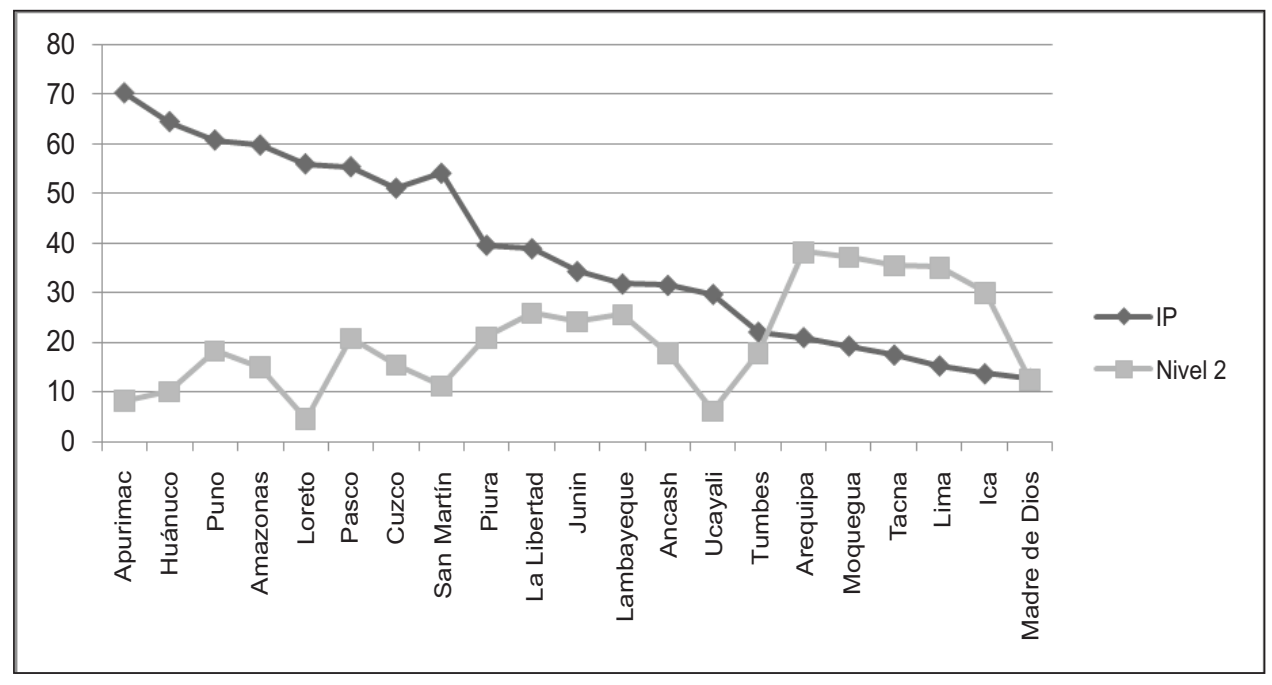

Figura 1. Relación entre pobreza y comprensión lectora a nivel nacional. IP: Índice de Pobreza. Nivel 2: Logro esperado en comprensión lectora al finalizar el segundo grado de primaria. Fuente: Evaluación Censal de Estudiantes - 2009, Encuesta Nacional de Hogares - ENAHO (2009). Los departamento de Ayacucho, Cajamarca y Huancavelica no tiene resultados en la Evaluación Censal por no haber alcanzado la cobertura requerida, a pesar de un conjunto de instituciones educativas fueron evaluadas. Elaboración propia

Así mismo, los resultados de la Evaluación Censal de Estudiantes 2009 (ECE2009) señalan que un $76.9 \%$ del total de estudiantes de $2^{\circ}$ grado de primaria no lograron aprendizajes satisfactorios en comprensión lectora, siendo este porcentaje mayor en zonas rurales con índices de pobreza elevado (88.4\%) que en las zonas urbanas (71.1\%) (Ver Tabla 1, Ministerio de Educación del Perú, 2010). 
Tabla 1

Diferencia de resultados ECE-2009 y ECE-2008 en comprensión lectora

\begin{tabular}{ccccccc}
\hline & & ECE-2009 & \multicolumn{2}{c}{ ECE-2008 } & & Diferencia \\
Logro & Urbanas & Rurales & Urbanas & Rurales & Urbanas & Rurales \\
& $\%$ & $\%$ & $\%$ & $\%$ & & \\
\hline Nivel 2 & 28,9 & 11,6 & 22,5 & 5,5 & $6,4 *$ & $6,1 *$ \\
Nivel 1 & 56,1 & 48,5 & 58,5 & 41,9 & $-2,4^{*}$ & $6,6^{*}$ \\
$<$ Nivel 1 & 15,0 & 39,9 & 19,0 & 52,6 & $-4,0^{*}$ & $12,7^{*}$ \\
\hline *Diferencias significativa al 5\% & & & & \\
\hline
\end{tabular}

Elaboración: MINEDU, 2010

Un estudio de carácter longitudinal realizado en Puno señala que niños no pobres que asisten a centros educativos urbanos, obtienen un mejor rendimiento en comprensión lectora que aquellos niños pobres de zonas rurales (Cueto, Guerrero, León, Cevallos \& Sugimaro, 2010). Las diferencias señaladas entre niños pobres y no pobres en el rendimiento lector podrían deberse a las mayores oportunidades para explorar el lenguaje escrito que brindan entornos más favorecidos social y económicamente. Esto evidencia, en el Perú, diferencias muy grandes en el desempeño de los alumnos, explicadas principalmente por el índice socioeconómico de los mismos. En ese sentido, se evidencia una incapacidad para encontrar los medios y las estrategias adecuadas que permitan enfrentar el grave problema de la comprensión lectora de nuestros estudiantes peruanos. Realidad que afecta no solo su rendimiento lector sino también que repercutirá sobre su calidad de vida.

El problema central del retardo lector no se encuentra en los aspectos perceptivos visuales ni psicomotores, sino en los aspectos psicolingüísticos referidos a la comprensión verbal, procesos sintácticos, semánticos y de conciencia fonológica, relacionados al conocimiento estructural y de operatoriedad sobre el lenguaje (Canales, 2004). Partiendo de un modelo de "Arquitectura funcional" de los procesos cognitivos y psicolingüísticos que intervienen en la lectura, tres son los tipos de procesos que intervienen en el aprendizaje lector: Procesos de bajo nivel (perceptivos), procesos de nivel medio (léxicos) y procesos de alto nivel (sintáctico y semántico) (Cueto, 2008).

Así, en la comprensión de un texto se conjugan una serie de operaciones que tienen que ver con la naturaleza multidimensional y multiestructural de la lectura (Kintsch \& Van Dijk, 1978), tal como lo señala la Figura 2. A nivel de la microestructu$r a$, se extraen las ideas y proposiciones del texto párrafo por párrafo para luego establecer una relación de continuidad secuencial y ordenación lógica entre ellos. 
En la macroestructura se extraen las ideas centrales para darle una significación global, una jerarquización ordenada y organizada al contenido textual. En este nivel se hace uso de las llamadas macro-reglas (Van Dijk, 1983). Existen tres tipos de macro-reglas. La primera es la de supresión, que permite seleccionar las proposiciones relevantes y eliminar las que no lo son. La segunda regla es la de generalización. Una vez seleccionadas las ideas centrales gracias a la operación cognitiva de la selección podemos ordenar la información de manera organizada y jerárquica estableciendo conceptos supraordenados y subordinados. Por último, la regla de integración o construcción permite suplantar una serie de proposiciones por una nueva que no aparece en el texto pero que subsume a las anteriores. El tercer nivel de procesamiento es el de superestructura, que alude al análisis de la presentación formal del texto. Existen textos expositivos, narrativos, científicos, literarios, etc.

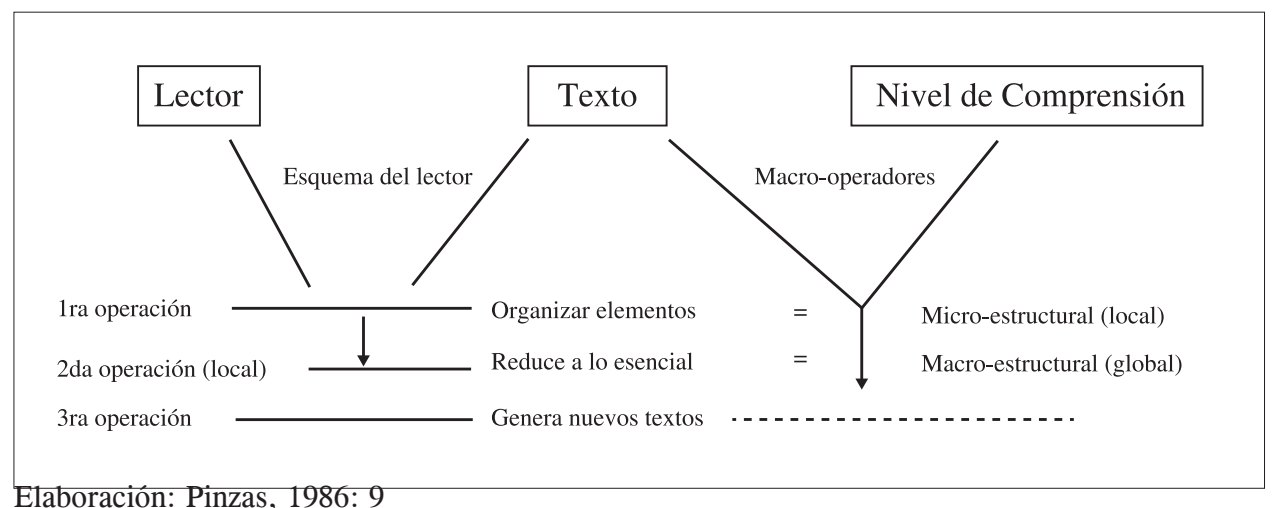

Figura 2. Esquema del modelo de lectura de Kintsch y Van Dijk (1978)

El carácter multidimensional de la lectura radica en el hecho de considerar que existen una serie de dimensiones que permiten obtener una representación mental del texto, lo que permite comprender la información escrita añadiendo a los contenidos literales nuestros conocimientos previos logrando así interpretar el modelo del mundo que el propio texto presenta a través de su autor para luego obtener un modelo mental propio útil en el desenvolvimiento diario.

Actualmente la comunidad científica reconoce la importancia de la lectura a través de distintas modalidades sin importar que el soporte del texto sea físico o electrónico. La transmisión de conocimientos y las competencias laborales exigen el dominio de la lectura; haciendo indispensable contar con metodologías que promuevan el aprendizaje lector de manera recreativa mediante textos interactivos, materiales audiovisuales e internet como elementos dinamizadores del aprendizaje, considerando las características y necesidades de niños y niñas, especialmente de zonas rurales cuyos resultados en las pruebas nacionales e internacionales son altamente deficientes. El empleo de las tecnologías de la información ha trans- 
formado las teorías, los materiales y los métodos de la lecto-escritura (Hartman, 2000), permitiendo que el niño se fije en el texto en sí, al mismo tiempo que en las imágenes, el sonido, etc., posibilitando una mayor comprensión del material que se está leyendo. Es importante señalar que el recurso informático no debe ser considerado un sustituto del maestro en el desarrollo de la comprensión lectora, más bien es un complemento a la actividad que este realiza diariamente en el aula (Kamil, Intrator \& Kim, 2000).

Los estudios acerca de la incorporación de tecnologías de la información para la enseñanza y aprendizaje de la lectura se vienen realizando hace más de 40 años. Investigadores de la Universidad de Stanford, utilizando programas informáticos computer assisted instruction, destinados a apoyar la enseñanza de la lectura, demostraron que aquellos estudiantes que utilizaron el programa lograron un rendimiento superior respecto de aquellos instruidos bajo métodos tradicionales (Fletcher \& Atkinson, 1972).

La lectura en formato hipermedial de carácter interactivo desarrolla habilidades necesarias para la comprensión y el aprendizaje como el uso del diccionario, análisis contextual, conocimiento de la información importante, capacidad de síntesis y el recuerdo de información (Henao, 2002). Los textos brindan al estudiante numerosa ayuda como ilustraciones y pronunciaciones digitalizadas para entender el vocabulario, preguntas diseñadas a apoyar la actividad metacognitiva (Anderson-Inman \& Horney, 1998), así como animaciones y diversos textos en que los niños puedan colorear, dibujar y crear sus propios relatos (Trushell, Burrell \& Maitland, 2001). Así, niños y niñas entre 8 y 9 años que participaron en un Programa Virtual de Entrenamiento en Lectura Significativa (e-PELS) lograron una mejora sustancial en su nivel de comprensión lectora y el dominio de las estrategias de aprendizaje incluídas en el programa comparados con un grupo control (Ponce, López, Labra, Brugerolles \& Tirado, 2007). Así también, aplicando un entorno hipermedial, estudiantes de primer año de educación secundaria elevaron su capacidad para identificar elementos morfosintácticos en imágenes, logrando avances en la búsqueda de los significados connotativos de las imágenes y la lectura de textos compuestos por palabras e imágenes (Villa, 2008).

Lo expuesto justifica realizar un estudio experimental acerca de la eficacia del uso de medios audiovisuales e internet en busca de un mejor nivel de comprensión lectora, lo cual exige una interpretación y orientaciones propias y permanentes.

\section{Objetivos}

\section{Objetivo General}

- Evaluar el efecto de un programa experimental interactivo para el mejoramiento

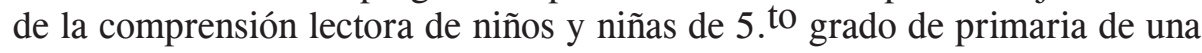
zona rural de la provincia de Yungay, Ancash (Perú). 


\section{Objetivos Específicos}

- Construir un programa interactivo lector para mejorar la comprensión lectora.

- Evaluar y comparar los niveles de comprensión lectora entre los niños y niñas de la muestra total.

- Evaluar y comparar los niveles de comprensión lectora en los niños y niñas del grupo experimental (pre y post test).

- Comparar los grados de avance en comprensión lectora de los niños y niñas sometidos al tratamiento (grupo experimental) y de los que no lo recibieron (grupo control).

\section{Hipótesis}

El nivel de comprensión lectora de los niños y niñas de $5 .{ }^{\text {to }}$ grado de primaria de una zona rural de la provincia de Yungay expuestos a un programa experimental interactivo se verá incrementado en mayor medida que el nivel de niños y niñas no sometidos al programa experimental.

\section{MÉTODO}

\section{Tipo de Investigación}

La presente investigación corresponde a un estudio experimental (Sánchez \& Reyes, 2006; Alarcón, 2008), en donde se estudia el efecto que produce un programa interactivo en el mejoramiento de la comprensión lectora.

\section{Diseño de Investigación}

Se aplicó un diseño experimental de dos grupos aleatorizados pre y post-test, en la medida que se produce una manipulación deliberada de las condiciones para producir un cambio en las variables observadas (Sánchez \& Reyes, 2006; Alarcón, 2008). Su diagrama es el siguiente:

\begin{tabular}{|l|l|l|l|l|}
\hline GE & $\mathrm{A}$ & $\mathrm{O}_{1}$ & $\mathrm{X}$ & $\mathrm{O}_{2}$ \\
\hline $\mathrm{GC}$ & $\mathrm{A}$ & $\mathrm{O}_{3}$ & - & $\mathrm{O}_{4}$ \\
\hline
\end{tabular}

En el esquema:

$\mathrm{GE}=$ Grupo experimental

$\mathrm{GC}=$ Grupo de control

$\mathrm{A}=$ Aleatorizado o al azar

$\mathrm{X}=$ Variable independiente $\mathrm{o}$ experimental.

O1, O2, O3, O4 = Variables observadas 


\section{Variables}

Variable Independiente: Programa informático para el mejoramiento de la comprensión lectora.

Variable Dependiente: Comprensión lectora de los niños y niñas evaluado a través del Test de Complejidad Lingüística Progresiva (CLP) de Alliende, Condemarin y Milicic (2002).

\section{Población}

La población objeto de estudio corresponde a niños y niñas de 5. to grado de primaria de zonas rurales de la provincia de Yungay en la región de Ancash (Perú); zona caracterizada por su bilingüismo, reducido vocabulario y escasos recursos económicos. Estas múltiples limitaciones dificultan el acceso a la lectura inicial ocasionando, más tarde, un retraso en la lectura y escritura (Zavala, 2002). La muestra inicial estuvo conformada por 100 niños, entre varones y mujeres, del $5{ }^{\text {to }}$ grado de educación primaria de 10 distritos de la zona, seleccionándose aleatoriamente los niños para los grupos experimental (50) y control (50). El número inicial de niños fue disminuyendo debido a circunstancias como incumplimiento de finalizar el programa, inasistencia a las sesiones, deserción, o por pertenecer a colegios unidocentes con escaso dominio del castellano. La muestra final quedó conformada por 80 niños, 40 en el grupo experimental y 40 en el grupo control.

Tabla 2: Distribución de la muestra final por grupo de estudio

\begin{tabular}{lcccccc}
\hline \multicolumn{1}{c}{ Sexo } & \multicolumn{2}{c}{ Experimental } & \multicolumn{2}{c}{ Control } & \multicolumn{2}{c}{ Total } \\
& $\mathrm{n}$ & $\%$ & $\mathrm{n}$ & $\%$ & $\mathrm{n}$ & $\%$ \\
\hline Varones & 18 & $45 \%$ & 18 & $45 \%$ & 36 & $45 \%$ \\
Mujeres & 22 & $55 \%$ & 22 & $55 \%$ & 44 & $55 \%$ \\
Total & 40 & $50 \%$ & 40 & $50 \%$ & 80 & $100 \%$ \\
\hline
\end{tabular}

\section{Instrumento}

Se utilizó la prueba de comprensión lectora de Complejidad Lingüística Progresiva (CLP) de Alliende, Condemarin y Milicic (2002) con normas peruanas (Delgado et al., 2005) para quinto grado de primaria que evalúa la capacidad del niño para categorizar, interpretar elementos simbólicos, caracterizar de manera adecuada personajes literarios y especificar el sentido de las palabras y expresiones de un texto (Alliende, Condemarin \& Milicic, 2002). Esta prueba consta de dos versiones (A y B). La versión A se utilizó para la evaluación antes de la aplicación del programa experimental, mientras la versión B después de la aplicación del mismo. Ambas versiones están constituidas por tres lecturas. El primero de los textos es de carácter descriptivo mientras los restantes de tipo narrativo. El estudio de 
confiabilidad de prueba se llevó a cabo con el método de test-retest obteniéndose un coeficiente rho de Spearman de .75, indicando que la prueba es confiable. Así mismo, la validez de constructo se efectuó mediante el análisis factorial confirmatorio, señalando que la prueba CLP para quinto de primaria está confromada por un solo factor, evidenciando validez de constructo (Delgado et al., 2005). La administración del mismo puede realizarse en forma individual y colectiva en aproximadamente 45 minutos.

\section{Procedimiento}

El procedimiento experimental fue aplicado previo consentimiento de las autoridades de los centros educativos seleccionados, dejando clara la completa libertad de participar o no en el estudio. Los instrumentos fueron aplicados de manera que fue factible obtener la información respectiva antes y después del programa experimental, asegurándose la confiabilidad de los resultados del estudio.

El programa experimental interactivo se elaboró teniendo como referente teórico el enfoque cognitivo de la lectura y teniendo a los medios audiovisuales e internet como soporte tecnológico. Consta de 30 lecturas interactivas organizadas en orden de dificultad y que contienen diferentes formas de ejercitar la comprensión lectora. Las lecturas están formadas por selecciones de contenidos variados que incluyen narración de experiencias, fábulas, descripciones, explicaciones, entre otros temas. Cada selección de textos está acompañada de una serie graduada de actividades que incluyen expresión oral, escrita, pictográfica y otras modalidades comunicativas, las cuales ejercitan las estructuras semánticas y sintácticas del lenguaje relacionándolas con los conocimientos previos del alumno referidos al contenido del texto. Al módulo van anexas actividades y tareas complementarias en formato de lápiz y papel para enriquecer las actividades y mantener el interés.

El programa experimental busca desarrollar las siguientes habilidades y destrezas en los alumnos: 1) Destrezas de estudio (Lectura de mapas, resúmenes y uso del diccionario y otras fuentes de referencia); 2) Destrezas linguísticas y literarias (Expresiones, ortografía, recursos literarios -comparaciones, metáforas y personificaciones-, morfología y sintaxis, vocabulario); 3) Expresión oral (Comentarios y descripciones, discusiones, explicaciones y narraciones); 4) Enjuiciamiento y apreciación (acciones, emociones, identificaciones y valores); 5) Memorización o recuerdo (cualidades, hechos o acciones, lugares, objetos, personajes, sentimientos, tiempo) y; 6) Pensamiento lógico (apreciación de juicios, asociación, clasificación, inferencia, generación de preguntas, seriación, semejanzas y diferencias).

El procedimiento de recolección de datos se realizó en tres momentos: 1) Pretest, en donde se evaluaron los dos grupos antes del desarrollo del programa; 2) Aplicación del programa al grupo experimental y, 3) Postest, evaluándose los dos grupos luego de finalizado el programa. En el procedimiento de procesamiento de datos se utilizó el paquete estadístico SPSS version 18 en español. 


\section{RESULTADOS}

La Tabla 3 permite visualizar el análisis comparativo antes del tratamiento entre el grupo experimental y el grupo control, indicándonos que no existen diferencias estadísticamente significativas en comprensión lectora $(\mathrm{t}=-.057, \mathrm{p}>.05)$, lo que confirma que los grupos presentan rendimientos similares antes de iniciar el tratamiento. Similar resultado se observa comparando las puntuaciones entre varones $(\mathrm{t}=.093, \mathrm{p}>.05)$ y entre mujeres $(\mathrm{t}=-.145, \mathrm{p}>.05)$. Estos resultados son reportados como convenientes para este tipo de estudios (Mc Guigan, 1996, Balluerka y Vergara, 2002).

Tabla 3: Análisis comparativo de comprensión lectora por grupo de estudio antes del tratamiento a través de la prueba t de Student.

\begin{tabular}{|c|c|c|c|c|c|c|}
\hline \multirow{2}{*}{ Escala } & \multicolumn{2}{|c|}{ Grupo Experimental } & \multicolumn{2}{|c|}{ Grupo Control } & \multirow{2}{*}{$\mathrm{t}$} & \multirow{2}{*}{ Sig. } \\
\hline & M & D.S. & M & D.S. & & \\
\hline Comprensión Lectora & 4.38 & 2.108 & 4.40 & 1.766 & -.057 & .954 \\
\hline Varones & 4.22 & 1.801 & 4.17 & 1.790 & .093 & .927 \\
\hline Mujeres & 4.50 & 2.365 & 4.59 & 1.764 & -.145 & .886 \\
\hline
\end{tabular}

No significativo $\mathrm{p}>.05$

El análisis comparativo después del tratamiento entre el grupo experimental y el grupo control (Tabla 4) denota la existencia de diferencias significativas en comprensión lectora $(\mathrm{t}=6.923, \mathrm{p}<.05)$. Así mismo, comparando varones $(\mathrm{t}=6.989$, $\mathrm{p}<.05)$ y mujeres $(\mathrm{t}=3.605, \mathrm{p}<.05)$ antes y después del tratamiento, se observan diferencias significativas en ambos grupos. En todos los casos los resultados alcanzados en el postest por el grupo experimental son mayores que los alcanzados por el grupo de control, lo que comprueba la eficacia del programa para el desarrollo de la comprensión lectora, utilizando medios audiovisuales e internet como soportes tecnológicos.

Tabla 4: Análisis comparativo de comprensión lectora por grupo de estudio después del tratamiento a través de la prueba t de Student.

\begin{tabular}{lcccccc}
\hline \multirow{2}{*}{ Escala } & \multicolumn{2}{c}{ Grupo Experimental } & \multicolumn{2}{c}{ Grupo Control } & $\mathrm{t}$ & \multirow{2}{*}{ Sig. } \\
& $\mathrm{M}$ & D.S. & $\mathrm{M}$ & $\mathrm{D} . \mathrm{S}$. & & \\
\hline Comprensión Lectora & 9.90 & 2.158 & 7.10 & 1.374 & 6.923 & $.000^{*}$ \\
Varones & 10.56 & 1.723 & 6.89 & 1.410 & 6.989 & $.000^{*}$ \\
Mujeres & 9.36 & 2.361 & 7.27 & 1.352 & 3.605 & $.001 *$ \\
\hline
\end{tabular}

Significativo $* \mathrm{p}<.05$ 
La Figura 3 muestra la igualdad estadística de las puntuaciones antes de aplicado el tratamiento entre el grupo experimental y control así como la diferencia significativa alcanzada luego de aplicado el programa experimental de comprensión lectora a favor del grupo experimental.

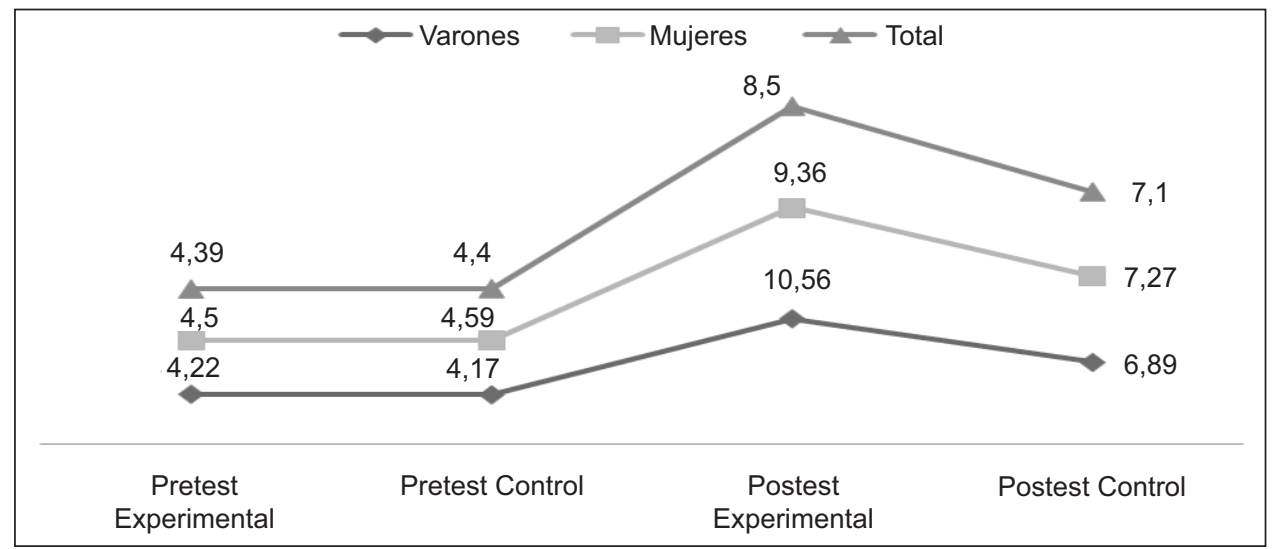

Figura 3. Comparación entre los grupos experimental y control antes y despúes del tratamiento experimental

El análisis comparativo antes y después del tratamiento en el grupo experimental, visualizado en la Figura 3 y presentado en la Tabla 5, permite apreciar la existencia de diferencias significativas entre los dos momentos $(t=-14.861, p<.05)$, evidenciando que el postest es mayor que el pretest. Tomando en consideración la variable género, se observa que tanto varones $(\mathrm{t}=-10.864, \mathrm{p}<.05)$ como mujeres $(t=-9.291, p<.05)$, han obtenido avances significativos luego de aplicado el programa, siendo los varones quienes presentan una mayor diferencia. Toda esta información corrobora la efectividad del programa interactivo en el desarrollo de la comprensión lectora.

Tabla 5: Análisis comparativo de comprensión entre el pretest y postest del grupo experimental

\begin{tabular}{lcccccc}
\hline \multirow{2}{*}{ Escala } & \multicolumn{2}{c}{ Pretest } & \multicolumn{2}{c}{ Postest } & $\mathrm{t}$ & Sig. \\
& $\mathrm{M}$ & D.S. & $\mathrm{M}$ & $\mathrm{D} . \mathrm{S}$. & & \\
\hline Comprensión Lectora & 4.39 & 1.932 & 8.50 & 2.284 & -14.861 & $.000^{*}$ \\
Varones & 4.22 & 1.801 & 10.56 & 1.723 & -10.864 & $.000^{*}$ \\
Mujeres & 4.50 & 2.365 & 9.36 & 2.361 & -9.291 & $.000^{*}$ \\
\hline
\end{tabular}

Significativo $* \mathrm{p}<.05$

Por otro lado, al comparar las puntuaciones entre varones y mujeres no se observan diferencias, tanto el pretest como postest (Tabla 6). 
Tabla 6: Análisis comparativo de comprensión entre el pretest y postest del grupo experimental según el sexo

\begin{tabular}{|c|c|c|c|c|c|c|}
\hline \multirow{2}{*}{ Escala } & \multicolumn{2}{|c|}{ Varones } & \multicolumn{2}{|c|}{ Mujeres } & \multirow{2}{*}{$\mathrm{t}$} & \multirow{2}{*}{ Sig } \\
\hline & M & D.S. & M & D.S. & & \\
\hline Pretest & 4.22 & 1.801 & 4.50 & 2.365 & -.806 & .422 \\
\hline Postest & 10.56 & 1.723 & 9.36 & 2.361 & .785 & .435 \\
\hline
\end{tabular}

\section{DISCUSIÓN}

El aprendizaje de la lectura es un signo de alfabetización y la puerta de entrada a la educación (Tapia, 2003). El estudio evalúa la eficacia de un programa instruccional interactivo de comprensión lectora que pueda ser empleado, de manera flexible, en los centros primarios de educación rural. Los análisis presentados llevan a aceptar la hipótesis planteada, avalando la eficacia del programa interactivo lector en el mejoramiento de la comprensión lectora.

Varias pueden ser las explicaciones para este hallazgos. El empleo de recursos multimedia permite al niño fijarse en el texto en sí, al mismo tiempo que en las imágenes, el sonido, etc., posibilitando una mayor comprensión del material que se está leyendo (Sandoval, 2009). Así mismo, permite un mayor control de su propio aprendizaje, ayudándoles a tomar sus propias decisiones, mejorando su concentración y evitando el aburrimiento (Hill, 1989), compartiendo con otros sus producciones, desarrollando la creatividad, originalidad y flexibilidad verbal. El grado que están cursando los niños y niñas al momento del estudio puede ser también un factor explicativo importante. Niños y niñas muestran mayor predisposición a utilizar herramientas sofisticadas en los niveles superiores de la Primaria (Mott \& Klomes, 2002). Así mismo, el empleo de la internet puede convertirse en un factor importante en nuestros resultados, en donde la disponibilidad de recursos multimediales e hipertextuales a través de una variedad de documentos y la posibilidad de cierta interacción mediante programas específicos en los ordenadores, contribuye en el disfrute de los materiales y la realización de actividades de lectura (Paredes, 2005).

De manera adicional, y coincidiendo con otros estudios (Anderson, 1993; Cueto, Jacoby \& Pollitt, 1997) los resultados reportan que, en el grupo experimental, tanto varones como mujeres alcanzan mejores desempeños en el postest a comparación del pretest. Los desempeños logrados por ambos grupos (varones y mujeres) luego del tratamiento experimentales no difieren estadísticamente, lo que hace suponer que la variable género no contribuye a la variabilidad del nivel de comprensión lectora luego de la intervención. Este hallazgo coincide con lo reportado en la evaluación censal de estudiantes 2009, que no muestra diferencias significativas en relación al género en comprensión lectora (Ministerio de Educación del Perú, 2010). Así las causas de las diferencias en comprensión lectora radican probable- 
mente en el programa informático mismo o variables socioculturales (experiencias vivida, como el número de horas de clases o expectativas culturales) y no en un origen biológico (Cueto, Jacoby \& Pollitt, 1997).

Así mismo, si bien se observa un incremento de las puntuaciones de comprensión lectora, estos aún no son totalmente satisfactorios, lo que sugiere que podría haber factores de la comunidad, de la escuela (textos, materiales educativos, etc.), de los padres (nivel educativo, nivel socioeconómico, etc.), de los niños (historia educativa, horas de estudio y trabajo en casa, etc.) o alguna interacción entre ellos que funcionen como predictor del desempeño, independientemente de la intervención experimental (Cueto, Jacoby \& Pollitt, 1997; Cueto, 2007; Cueto \& León, 2010). Este rendimiento previo es el principal factor del rendimiento posterior, ya que lo que cada estudiante aprende va determinando lo que puede aprender después. Esto resalta la importancia de contar con programas de apoyo a los estudiantes dentro del propio sistema (Cueto et al., 2010; Cueto \& Secada, 2004).

Nuestros resultados no pretenden mostrar que la utilización de herramientas informáticas y telemáticas sea necesariamente la única alternativa eficaz para un mejor desarrollo de la comprensión lectora. No es conveniente sobredimensionar las virtudes pedagógicas y didácticas de estas tecnologías, pero tampoco minimizar su potencial. Las tecnologías de la información y comunicación (TIC) no innovan o cambian algo por el solo hecho de introducirse en las instituciones educativas. El reto es avanzar hacia la construcción de ambientes y estrategias de enseñanzaaprendizaje que aprovechen, de manera creativa y crítica, los nuevos espacios de lectura que ofrecen las TIC (Henao, 2006). Dados los niveles de pobreza de los niños y niñas de ambientes rurales, el bilingüismo y los bajos niveles educativos de los padres, el Estado peruano debería proveer de programas especiales para estos niños, como el que se propone, buscando un rendimiento similar al de sus pares urbanos (Cueto \& León, 2010).

La metodología experimental del estudio es importante por su capacidad para demostrar los efectos del programa interactivo a diferencia de los estudios descriptivos exploratorios o no-experimentales que carecen de poder explicativo. La experimentación, al brindar al investigador la oportunidad de introducir los cambios necesarios en los procedimientos y observar sus consecuencias, contribuye con un nivel de veracidad objetiva de los hallazgos sin par en la metodología científica. Si la investigación está bien planteada, sus resultados serán particulares, relevantes y prácticos, lo que favorecerá su utilización por parte de los encargados de las tomas de decisiones públicas.

Es pertinente señalar la existencia de limitaciones en el estudio. Primero, los participantes conforman una muestra pequeña, por lo que los resultados no son generalizables a toda la población rural del Perú, recomendándose, en estudios posteriores, se incluyan otros grupos urbanos y rurales del Perú. Respecto al programa experimental interactivo, se sugiere brindar mayor asesoría a los docentes en la utilización de materiales informáticos en sus clases, así como la implementación de la intervención interactiva por un mayor periodo de tiempo, considerando el 
mayor tiempo que algunas habilidades necesitan de para su desarrollo. Todo este trabajo se debe complementar con un programa de seguimiento que incluya procedimientos de observación en clase. De esta manera, la retroalimentación sería más efectiva y la propuesta de intervención podría ser evaluada de mejor manera.

\section{CONCLUSIONES}

1. El programa interactivo lector empleado en el presente estudio ha mostrado eficacia en el mejoramiento de la comprensión lectora en el sector rural de la provincia de Yungay, Ancash (Perú).

2. Las diferencias encontradas en la evaluación de la comprensión lectora luego de aplicado el tratamiento experimental entre el grupo de control y experimental son significativas.

3. Las diferencias encontradas entre las evaluaciones de la comprensión lectora, antes y después de la situación experimental, son significativas.

\section{NOTA DE RECONOCIMIENTO}

Los responsables brindan su reconocimiento a las autoridades y docentes de los centros educativos en donde se llevaron a cabo el estudio, por su colaboración en la aplicación de los instrumentos y, de manera especial, a los alumnos, cuyo aporte ha permitido obtener la información necesaria para la presente investigación.

\section{REFERENCIAS BIBLIOGRÁFICAS}

Alarcón, R. (2008). Métodos y diseños de investigación del comportamiento ( $2^{\circ}$ ed.). Lima: Ed. Universitaria.

Anderson, J. (1993). Desde niñas. Género y postergación en el Perú. Lima: UNICEF y Consorcio Mujer.

Anderson-Inman, L. \& Horney, M. A. (1998). Transforming Text for At-Risk Readers. En Reinking, D. (editor). Handbook of Literacy and Technology. Transformations in a Post- Typographic World (pp. 15-43). Mahwah, NJ: Lawrence Erlbaum Associates.

Balluerka, N. \& Vergara, I. (2002). Diseños de investigación experimental en psicología. Madrid: Prentice Hall.

Canales, R. (2004). Psicología y problemas de aprendizaje: Factores cognitivos, lingüísticos y socioculturales que intervienen en el aprendizaje de la lectura. Revista de Psicología, 7(1), 107-124.

Cuetos, F. (2008). Psicología de la lectura. Madrid: S.A. Wolters Kluwer.

Cueto, S., Jacoby, E. \& Pollitt, E. (1997). Rendimiento de niños y niñas de zonas rurales y urbanas del Perú. Revista de Psicología, 15(1), 115-133.

Cueto, S. \& Secada, W. (2004). Oportunidades de aprendizaje y rendimiento en matemática de niños y niñas aimara, quechua y castellano hablantes en escuelas bilingües y 
monolingües en Puno, Perú. En Winkler, D. \& Cueto, S. (editores) Etnicidad, raza, género y educación en América Latina (pp. 315-354). Washington D. C.: PREAL

Cueto, S. (2007). Las evaluaciones nacionales e internacionales de rendimiento escolar en el Perú: Balance y perspectivas. En GRADE (editor). Investigación, Políticas y Desarrollo en el Perú (pp. 405-455). Lima: Grupo de Análisis para el Desarrollo.

Cueto, S., Guerrero, G., León, J., Zevallos, A. \& Sugimaru, C. (2010). De quinto de primaria al fin de la secundaria en seis años: un estudio longitudinal en Puno. Documento de trabajo, 56. Lima: Grupo de Análisis para el Desarrollo, Consorcio de Investigación Económica y Social.

Cueto, S. \& León, J. (2010). Oportunidades y resultados educativos en la educación básica en el Perú. En Portocarrero, F., Vásquez, E. \& Yamada, G. (Editores). Políticas Sociales en el Perú. Nuevos Desafios (pp. 69-101). Lima: Pontificia Universidad Católica del Perú, Universidad del Pacífico, Instituto de Estudios Peruanos, Red para el Desarrollo de las Ciencias Sociales en el Perú.

Dioses, A., Evangelista, C., Basurto, A., Morales, M. \& Alcántara, M. (2010). Procesos cognitivos implicados en la lectura y escritura de niños y niñas del tercer grado de educación primaria residentes en Lima y Piura. Revista de Investigación en Psicología, 13(1), 13-40.

Fletcher, J. \& Atkinson, R. (1972). Evaluation of the Standford CAI Program in Inicial Reading. Journal of Educational Psychology, 63(6), 597-602.

Hartman, D. (2000). What will be the Influences of Media on Literacy in the Next Millenium? Reading Research Quarterly, 35(2), 281-282.

Henao, O. (2002). La construcción de mapas semánticos en un texto hipermedial e impreso. Revista Educación y Pedagogía, 14(33), 243-254.

Henao, O. (2006). Evidencias de la investigación sobre el impacto de las tecnologías de la información y comunicación en la enseñanza de la lectoescritura. Revista Educación y Pedagogía, 18(44), 71-87.

HILL, S. (1989). Reading, Writing, and Computers, Needham Heights: MA Allyn and Bacon

Kamil, M., Intrator, S. \& Kim, H. (2000) The effects of other Technologies on literacy and literacy learning. En Kamil, M., Mosenthal, P., Pearson, P. \& Barr, R. (Eds.). Handbook of Reading Research (Vol III, pp. 771 - 788). Mahwah, NJ: Lawrence Erlbaum Associates.

Kintsh, W \& Van Dijk, T. (1978). Toward a model of test comprehension and production. Psychological Review, 85, 383-394.

Mc Guigan, J. (1996) Psicología Experimental. México: Ed. Trillas.

Ministerio de Educación del Perú (2010). Evaluación Censal de Estudiantes 2009. Lima: Autor.

Morales, S., Verhoeven, L. \& Van Leeuwe, J. (2009). Programa de comprensión lectora para alumnos de quinto grado de primaria de Lima. Revista de Psicología, 27(1), 80-110. 
Mott, M. \& Klomes, J. (2002). The synthesis of writing workshop and hipermedia authoring: grades 1-4. Early childhood research and practice, 3 (2), 34-45.

OECD \& PIZA (2010). PISA 2009 Result. Recuperado de http://www.pisa.oecd.org/do cument/61/0,3746,en_32252351_32235731_46567613_1_1_1_1,00.html.

Paredes, J. (2005). Animación de la lectura y TIC. Creando situaciones y espacios. Revista de Educación, número extraordinario, 255-279.

Pinzas, J. (1986). Del símbolo al significado. El caso de la comprensión de lectura. Revista de Psicología, 4(1), 3-13.

Pollitt, E., León, J. \& Cueto, S. (2007). Desarrollo infantil y rendimiento escolar. En GRADE (editor). Investigación, Políticas y Desarrollo en el Perú (pp. 486-535) Lima: Grupo de Análisis para el Desarrollo.

Pollitt, E. \& Caycho T. (2010). Desarrollo motor como indicador del desarrollo infantil durante los primeros dos años de vida. Revista de Psicología, 28(2), 385-413.

Ponce, H., López, M., Labra, J., Brugerolles, J. \& Tirado C. (2007). Evaluación experimental de un programa virtual de entrenamiento en lectura significativa (e-PELS). Revista Electrónica de Investigación Psicoeducativa, 12, 5(2), 399-432.

Sánchez, H. \& Reyes, C. (2006). Metodología y Diseños en la Investigación Científica. Lima: Ed. Visión Universitaria.

Tapia, V. (2003). Programa Psicopedagógico de Comprensión Lectora. Aprendo a pensar a través de la lectura. Lima: Facultad de Psicología de la Universidad Nacional Mayor de San Marcos.

Trushell, J.; Burrell, C.; Maitland, A. (2001).Year 5 pupils reading an interactive storybook on CD-ROM: losing the plot? British journal of educational technology, 32 (4), 389-481.

Van Dijk, T. (1983). La ciencia del texto. Barcelona: Paidós.

Villa, N. (2008). Propuesta de alfabetización visual para estudiantes de educación básica apoyada en recursos hipermediales. Un aporte a la comprensión lectora. Revista Interamericana de Bibliotecología, 31(1), 207-225.

Zavala, V. (2002). (Des) encuentros con la escritura. Escuela y comunidad en los Andes Peruanos. Lima: Red para el Desarrollo de las Ciencias Sociales en el Perú. 
